\title{
On the Development of College Student Information Management System
}

Anjiang Jin

Huazhong Agricultural University, 430070, Wuhan, Hubei, China

\begin{abstract}
. currently there exist severe fragmentation, different development standards, lack of sufficient support and other problems in the development of college student information management system. Therefore accelerating the development of student information management system is of necessity to improve universities' management and administration efficiency. From the perspective of customers' demands, the system should be designed and developed on the basis of Web Service by adopting B/S structure and SQL Server technology so as to coordinate applicability, security, compatibility, stability, maintainability and other non-functional demands.
\end{abstract}

Keywords. colleges and universities; students; information management system; development

Under the background of increasing quality of higher education and the rapid enrollment expansion, to develop student information management system (SIMS) is of great significance to enhance efficiency in student management and accomplish the updating, instant inquiry and longterm preservation of students' overall development information data including their education background, academic performance and practice. Yet colleges and universities in China as a whole remain at the initial stage in terms of SIMS development, which hardly meets daily demands in work. Thus it is urgent to promote the design of college student information management system (CSIMS), develop unified information platform and then promote the informatization in all aspects.

\section{Problems in the development of CSIMS}

\subsection{Different understanding of the importance of developing information management system}

Building an information system is a complex systematic project. The development of CSIMS involves a number of schools and functional departments in charge of student education, management, service and others. It also requires rebuilding the previous working process and designing a new one based on information technology. However, so far a unified view on the importance of SIMS hasn't been formulated among universities. For example, some teachers not paying enough attention to it think that its benefits are limited while some feel it difficult to develop. Still a part of teachers and students with insufficient IT knowledge aren't skilled in 
information tools and then lower their interest in developing information system, which therefore affects overall development of information management system (IMS) in universities.

\subsection{Severe fragmentation in the current IMS}

Currently CSIMS still adopts the model of bull management and decentralized development in conformity with the traditional division of functional departments. Accordingly the logging, backuping, storing, processing, spreading and use of the data will be conducted by each of departments in charge of information management. For instance, departments in charge of teaching affairs, student affairs and finance will respectively develop their own information systems. As a result, these systems will not be compatible to each other, leading to repetitive storage of information, inconsistent data and information isolated islands.

The bull management could lead each department to hand out forms to students in order to collect the needed data. The repetitive work would add extra burden to students as information provider and reduce information processing efficiency and validity. Meanwhile it could spread universities' limited resources for informatization with improper repetitive consumption of resources and lowered usage effectiveness.

\subsection{Different development standards for CSIMS}

Differences exist among CSIMSs because currently a unified development standard for CSIMS has yet been introduced. For example, there are different characteristics in hardware facility input, function design of the system, technology adoption as well as the content and scope of collected students' information. It causes the incompatibility among CSIMSs at the regional or even the national level. In the era of big data therefore a unified development standard should be carried out as soon as possible to guide the building of CSIMS and then achieve their inter-connection, comparison and sharing.

\subsection{Incomplete support system for the development of IMS}

(1) Lacking strong technological support. Due to the rapid development of database technology the development of CSIMS arrives at a crucial stage. New technologies often bring great changes and breakthroughs, which is both an opportunity and a challenge to the building of CSIMS for universities. Yet the informatization in colleges and universities currently remains at the early stage when their database usually adopts Access, VF and VB operating platform. These technologies can only meet simple demands for office and cannot be used to operate complex information system. Although some universities use SQL Server and other large databases, information overload is so severe that it affects the overall operation efficiency of the information system.

(2) Lacking sufficient financial support. Financial resource is essential for universities to carry out the building of information system. For instance, at the stage of system development, the sufficient financial input is needed for the high throughput hardware facilities required by the information system development as well as the information system software meeting its demand. The post maintenance and updating need continuous financial input as well. Some universities have already been equipped with information system but have no supporting fund for system updating and upgrading, which leads to improper system operation and then fails to realize expectations.

(3) Lacking intellectual support. As the most valuable resource human resource plays a key role in determining whether the system can operate constantly and effectively or not. Featuring fast pace of updating and the complex structure, CSIMS has a specially strict requirement on relevant staff's technological skills because the success and effectiveness of the whole system development are directly influenced by staff's computer skills, comprehensive quality and the sense of 
responsibility. Therefore, the maintenance of SIMS needs inter-disciplinary talents who have a wide knowledge of school registration management, file management and computer skills. However, the staff in charge of school registration and file management in universities currently aren't excel in computer operation due to their older age followed by little knowledge of it. It means that we should employ more the above-mentioned type of talents and promote training in order to avoid the situation that the shortage of talents affects the development and utilization of information system.

(4) Lacking supporting system. The application of IT methods will exert revolutionary effects on the existing student management model. So we have to rebuild the working process of student management, review and formulate relevant mechanisms in accordance with the operation of SIMS. In some universities which have tried to spread SIMS, the failure to effectively integrate IT methods with the traditional management system has affected the usage of information system. Hence the development of SIMS needs the overall reform of student management model and the completion of supporting system.

\section{The basic thinking of the development of CSIMS}

As an application-oriented software system, CSIMS have to be developed in the following six steps. Firstly, we should analyze the demand on system in order to have a full understanding of users' demands on the system. Secondly, we should design system functions and work out its basic functions. Thirdly, we should design data structure and logical relationship and substantially develop the system. Fourthly, we should design modules and develop basic modules. Fifthly, we should assess the system and improve the last two steps according to the assessment result. At last, we should produce system files and submit them to users. Among them the key is mapping the general system function structure because it can clarify the organization and transfer relationship among functions of the whole CSIMS so as to produce ports between modules and then straighten up thinking for the next detailed design and system development.

Besides, attention should be paid to meeting several non-functional demands when developing SIMS.

Firstly, it is practicability. Practicability is the most basic requirement for information system as well as the prior one considered in the system development. At least the following aspects should be taken into account in CSIMS. Firstly, it should have abundant functions which can serve the majority of works relevant to student management and suitable to IT processing. Secondly, it should be convenient in operation and reasonable in system functional structure so as to conform with the practical working process. Thirdly, it should be much open and suit various users, and support their operations in different modules according to their responsibility and authority.

Secondly, it is security. Security is an important factor which has to be considered in the system development. Students' privacy and property security are directly related to their basic information, financial information and grade information managed and stored by SIMS. Therefore they have to be encrypted with corresponding security level in order to avoid the situation that in the open Internet environment the system information could be tampered or eavesdropped by hackers causing losses to students and universities.

Thirdly, it is stability. Stability is a crucial factor in ensuring the efficient and smooth operation of the system. Students' course selection and score registration are conducted in a phased manner, which means that in a short period a great number of users will log in CSIMS simultaneously. Therefore, in the system development we should ensure that the system will keep instant response to a great deal of concurrent access and decrease response time as well in order to avoid system crash caused by excessive user traffic or wrong use.

Fourthly, it is compatibility. Compatibility is a crucial factor determining whether the system can be promoted for wide application or not. CSIMS should include those functions needed by different schools and functional departments in charge of teaching affairs, student affairs, finance, the library and logistics. Thus the single system can satisfy all-round needs of student education, 
management and service. Meanwhile, the system should adopt open interface design in order to make convenient the system upgrading and second development. Besides, the system should be compatible with different operating systems such as Windows, Linux and Android, and with different login ways by computer, phone or pad.

Fifthly, it is maintainability. Maintainability is an important factor determining the service life of the system. The system maintenance should be brief as much as possible with friendly operation interface and the situation should be avoided when maintainer's misoperation causes system breakdown. In addition, the maintenance cost should be cheap as much as possible.

\section{User-centered design of CSIMS}

Being user-centered is a basic principle for CSIMS design. According to the practice in student information management in Huazhong Agricultural University (HZAU), the paper proposes a user-centered CSIMS development model. The system is mainly oriented to two user groups, the student and the functional department (or the school). Both serve as information provider and user, or information input terminal and output terminal. Also they can process business online and different users will conduct relevant operation within their authority after entering different systems in accordance with their management authority.

The system function should be designed based on users' demands, which means that it should be compatible with those functions needed by different users including students, schools, the library and functional departments in charge of teaching affairs, student affairs, finance and logistics. The function design meeting the practical needs should undergo the joint consultation between users and technicians before its completion. Meanwhile the working process should be rebuilt. At first the system provides a login interface for users to input login information. The system will check their name and password to confirm the access right after users submit login request. Because of the diversified functions in the system different right control strategies are needed for different users when they enter the information portal. And then authorization should be conducted upon users according to their login information so as to ensure every user can have proper access to their legal rights. After the login students can input basic information, enroll for the semester, select courses, study online courses, apply for the scholarship and grant, record their own comprehensive performance, pay the tuition fee, and inquire the school report and the finance. With the system the department of teaching affairs can update online courses, input the service condition of the classroom, and record student score. Meanwhile the department of student affairs can examine and approve students' basic information, application for the scholarship and grant, and register students' employment and dispatch information. The library, the logistics department, the financial department, schools, teachers and instructors have corresponding functions in the system based on their different needs and they are endowed with corresponding rights to inquire, input and revise information.

From the perspective of Web Service CSIMS will be designed and developed with the adoption of B/S structure and SQL Server. A top-down design will be carried out to divide the function modules of the system and the gradation of the software. And then the work begins with specific function modules in order to complete the single-module. At last each of function modules will be integrated to formulate the whole system. The database should have the functions of analysis, inquiry and derivation and can support cloud computing to inquire, count, compare and derive information so as to make full use of big data. The system should have a human-computer interface to guide users' visit and use, and it should be convenient to update and maintain the system.

The key to be user-centered is to strengthen the building of the peripheral supporting system of CSIMS. To achieve the goal we should take following steps. Firstly, we should spread IT knowledge with training on information skills so as to provide relevant talents for the wide application of the system. Secondly, we should enhance financial support by establishing specific funds to build and maintain the IMS. Thirdly, we should reform the student management model as 
a whole by reexamining and formulating the working mechanism in accordance with CIMS in order to rebuild the working process of student management. Fourthly, we should pay attention to users' new demands on the system, update and upgrade the system timely so as to meet the developing needs on student management.

\section{References}

1. Miaoling Gao, Chao Zhang. Considerations on the Construction of Management System for Student-related Information in Colleges and Universities [J]. Social Sciences Journal of Universities in Shanxi. 2012, 24(4): 104-107.

2. Tiyun Huang, Yijun Li. Management Information System [M]. Beijing: Higher Education Press, 2009.

3. Chengjun Lu. Design of College Student Information Maneagement System with ASP. NET 2.0 Technology. Journal of Chongqing University of Arts and Sciences (Natural Science Edition). 2009, 28(4): 38-42.

4. Zhiqiang Wang. Entry to Management Informtion System [M]. Beijing: Tsinghua University Press, 2005: 15-30.

5. Stephen Haag, Maeve Cummings. Management Information Systems for the Information Age [M]. New York: McGraw-Hill, 2011: 32-47.

6. Frans Kaashoek. Principles of Computer System Design [M]. Singapore: Elsevier, 2009: 7-20. 